\title{
Slurry Dewatering Process to Improve Quality of Low Grade Coal
}

\author{
Hartiniati $^{1}$
}

\begin{abstract}
The upgrading Kalimantan low rank coal is performed using slurry dewatering process in a stirred batch autoclave (inner volume of 5 liters) equipped with a condenser, a pressure control valve (PCV), and a receiver. The experiment is carried out at $3.5 \mathrm{~kg} / \mathrm{cm}^{2} \mathrm{G}$ nitrogen pressure, $250^{\circ} \mathrm{C}$ heater temperature and $150 \mathrm{rpm}$ agitator speed. Kerosene and low sulfur waxy residue (LSWR) are used as oil solvents. The fluidity of slurry is studied with the ratio of oil to coal $(\mathrm{O} / \mathrm{C})$ at 1.5 to $2 \mathrm{wt} / \mathrm{wt}$ and the concentration of LSWR at 0.5 to $2 \%$ in oil. The temperature profile during operation is evaluated to investigate the process performance. Moreover, pH, TSS and TDS contents in water product is also analyzed. A centrifuge separator (cap. 200 gram, $1000 \mathrm{rpm}$ ) is used to remove oil in coal slurry, and it is found that almost all added oil can be recovered. The study suggests that calorific value of upgraded coal (as received basis) increases sharply from $5,178 \mathrm{kcal} / \mathrm{kg}$ to $7342 \mathrm{kcal} / \mathrm{kg}$, following drastic reduction in total moisture, from $25,5 \%$ to $4,97 \%$. The contents of ash, volatile matter and elements do not change very much from that of raw coal. This phenomenon shows that no chemical reaction occurs in the process. The wastewater from the process is clean enough thereby a simple wastewater treatment is required in commercial plant. Re-absorption test shows that stable moisture content in coal is achieved at $\mathbf{7 . 5}$ wt $\%$ for 13 days. The temperature profile suggests that the slurry dewatering process can be applied effectively to Kalimantan low rank coals producing excellent upgraded coal characteristics.
\end{abstract}

Keywords-Low Grade Coal, Slurry Dewatering, Upgrading

\section{Pendahuluan}

$\mathrm{B}$ atubara merupakan salah satu sumberdaya energi alternatif yang paling potensial di Indonesia mengingat jumlah cadangannya yang besar melampaui minyak dan gas. Namun potensi batubara yang besar tersebut pada kenyataannya belum dimanfaatkan secara maksimal. Salah satu kendalanya adalah, hampir $60 \%$ dari seluruh total cadangan batubara yang ada merupakan batubara muda yang tidak memiliki nilai jual baik (non-marketable) karena nilai kalornya yang rendah (3500-4000 kkal/kg) dan kadar airnya yang tinggi (>30\%). Hal ini menyebabkan kesulitan dalam penyimpanan dan biaya pengangkutan per kalori menjadi sangat mahal. Kenyataan tersebut menghambat kemungkinan eksploitasi potensi batubara Indonesia secara besar-besaran [6].

Untuk dapat digunakan sebagai produk batubara yang bernilai tinggi, tantangannya adalah bagaimana meningkatkan kualitas batubara yang rendah tersebut menjadi layak jual, yang dicirikan dengan nilai kalor yang tinggi, aman dalam penyimpanan, dan pengangkutannya juga

\footnotetext{
Naskah diterima 5 Desember 2006; selesai revisi pada 1 April 2008

${ }^{1}$ Hartiniati adalah Peneliti Pusat Teknologi Pengembangan Sumberdaya Energi, BPPT Jakarta, INDONESIA

(e-mail: hartiniati@yahoo.com)
}

mudah dan murah. Disisi lain, pemanfaatan batubara juga sangat rentan dengan isu lingkungan. Oleh karena itu aplikasi teknologi batubara bersih, murah dan ramah lingkungan yang sekarang sedang berkembang secara pesat menjadi suatu keharusan.

Elemen paling penting yang merupakan konsep dasar dari setiap proses up-grading batubara adalah proses penghilangan kandungan air atau pengeringan (drying). Secara lebih sederhana, proses ini dapat meningkatkan nilai kalor, sehingga meningkatkan pula efisiensi dalam proses pembakaran [3],[4],[7].

Beberapa teknologi proses up-grading yang dikembangkan saat ini diantaranya dapat dilihat pada Tabel 1 . Berbagai proses tersebut dibedakan berdasarkan kondisi reaksinya, jenis media perpindahan panas, tipe reaktor, kualitas limbah cair dan biaya pengolahan.

Aplikasi teknologi proses up-grading batubara peringkat rendah harus mempertimbangkan beberapa kriteria penting yaitu layak secara tekno-ekonomi dan seminimal mungkin melibatkan perubahan kimiawi batubara. Ini berarti bahwa proses up-grading pada temperatur dan tekanan rendah lebih diinginkan agar proses-proses pelepasan senyawa organik atau proses pirolisa dapat ditekan sehingga limbah cair dan emisi gas yang dihasilkan hampir tidak ada. Operasi pada temperatur dan tekanan rendah juga akan menurunkan biaya operasi dalam jumlah yang sangat berarti.

Evaluasi awal menunjukkan bahwa proses Up-grading Brown Coal sangat menarik diterapkan untuk batubara muda Indonesia. Proses tersebut dirancang khusus menghasilkan produk batubara yang setara dengan subbituminus dan bituminus melalui teknik slurry dewatering[1],[2].

Proses dewatering dan stabilisasi (coating) berlangsung secara bersamaan sehingga pada saat pelepasan air dalam fase minyak menyebabkan fraksi minyak berat terabsorbsi ke dalam permukaan internal dari pori-pori batubara. Penyerapan minyak ke dalam struktur poripori batubara tersebut menyebabkan produk batubara yang dihasilkan tidak saja terbebas dari sifat mudah terbakar (spontaneous combustion free) tetapi juga tidak mudah menyerap air (re-wetting free).

Proses pelepasan air (dewatering) dalam batubara berlangsung secara fisika dan bukan secara kimia, sehingga air buangannya tidak terkontaminasi senyawa phenol dan senyawa organik lainnya. Selain itu, tidak melibatkan proses pirolisa maupun pelepasan emisi gas buang karena berlangsung pada temperatur maksimum $150^{\circ} \mathrm{C}$ dan tekanan maksimum 3,5 atm. Oleh karena kondisi operasinya yang rendah, sifat produk batubara yang dihasilkan diharapkan tidak banyak mengalami perubahan kecuali peningkatan nilai kalor (sampai sekitar $6500 \mathrm{kkal} / \mathrm{kg}$ ) dan penurunan kadar air serta stabil 
dalam penyimpanan. Keunggulan lainnya dari proses ini, peralatan dan operasionalnya relatif lebih murah karena beroperasi pada tekanan dan temperatur yang relatif rendah, sehingga dapat meningkatkan efisiensi energi $[5],[6]$.

TABEL 1

Berbagai TeKNologi Proses Up-Grading [4], [5]

\begin{tabular}{|l|l|}
\hline \multicolumn{1}{|c|}{ Prinsip } & \multicolumn{1}{|c|}{ Metode } \\
\hline Evaporasi & Flash method \\
& Steam tube dryer (STD) \\
& Steam fluidized bed dryer \\
& (SFBD) \\
& Slurry dewatering (UBC) \\
& SynCoal \\
\hline Non-evaporasi & Mechanical dewatering \\
& Fleissner process \\
& Hot water dewatering (HWD) \\
\hline Pirolisis & Encoal \\
& K-Fuel (Koppelman process) \\
\hline
\end{tabular}

Dalam tulisan ini, proses peningkatan kualitas (upgrading) batubara muda Indonesia yang diperoleh dari daerah Berau, Kalimantan Timur dievaluasi berdasarkan profil kondisi operasi selama proses slurry dewatering berlangsung. Selanjutnya, karakteristik produk batubara hasil up-grading dibandingkan dengan batubara umpan, termasuk kualitas air buangannya. Selain itu juga dilakukan investigasi pengaruh konsentrasi minyak (coating) serta kecenderungan produk batubara yang dihasilkan untuk menyerap air kembali (re-absorption).

Pengujian ini dilakukan menggunakan fasilitas labscale reaktor kapasitas 5 liter tipe batch di Laboratorium Pencairan Batubara, P3TKKE-BPPT, Kawasan PUSPIPTEK, Serpong, Tangerang.

\section{BAHAN DAN METODE}

\section{A. Batubara Muda}

Batubara yang digunakan dalam penelitian ini adalah batubara dari Kalimantan Timur (Berau Lati) yang diklasifikasikan sebagai batubara muda. Sebelum diumpankan ke dalam autoclave, batubara terlebih dahulu digerus de- ngan ukuran diameter partikel $-4,75 \mathrm{~mm}+2.36 \mathrm{~mm}$. Sedangkan umpan batubara untuk kebutuhan analisa proksimat, ultimat dan nilai kalor digerus hingga lolos 60 mesh.

\section{BAHAN DAN METODE}

\section{B. Batubara Muda}

Batubara yang digunakan dalam penelitian ini adalah batubara dari Kalimantan Timur (Berau Lati) yang diklasifikasikan sebagai batubara muda. Sebelum di umpankan ke dalam autoclave, batubara terlebih dahulu digerus dengan ukuran diameter partikel $-4,75 \mathrm{~mm}$ +2.36 mm. Sedangkan umpan batubara untuk kebutuhan analisa proksimat, ultimat dan nilai kalor digerus hingga lolos 60 mesh.

\section{Minyak Ringan dan Berat (coating agent)}

Minyak fraksi ringan dan berat dalam proses ini berperan sebagai coating agent. Minyak fraksi berat (heavy oil) yang digunakan merupakan residu minyak bumi, yaitu LSWR (Low Sulfur Waxy Residue). Sedangkan minyak fraksi ringan (light oil) yang di gunakan adalah minyak tanah (kerosine) yang juga merupakan produk fraksinasi minyak bumi.

Minyak berat dan minyak ringan sebelum digunakan didistilasi secara vakum pada $10 \mathrm{mmHg}$ untuk mengetahui fraksi LO (light oil), MO (middle oil) dan HO (heavy oil). Data hasil destilasi minyak tanah dan $L S W R$ ditunjukkan pada Tabel 2.

TABEL 2

HASIL FRAKSi DESTILASI MiNYAK

\begin{tabular}{|l|r|r|c|r|r|}
\hline \multirow{2}{*}{ Pelarut } & \multicolumn{5}{|c|}{ Fraksi Distilasi } \\
\cline { 2 - 6 } & $\mathbf{H}_{\mathbf{2}} \mathbf{O}$ & \multicolumn{1}{c|}{ LO } & \multicolumn{1}{c|}{ MO } & \multicolumn{1}{c|}{ HO } & \multicolumn{1}{c|}{ BTM } \\
\hline M. tanah & 0,00 & 34,45 & 63,48 & 0,80 & 2,07 \\
\hline LSWR & 16,72 & 0,00 & 10,98 & 17,56 & 54,74 \\
\hline
\end{tabular}

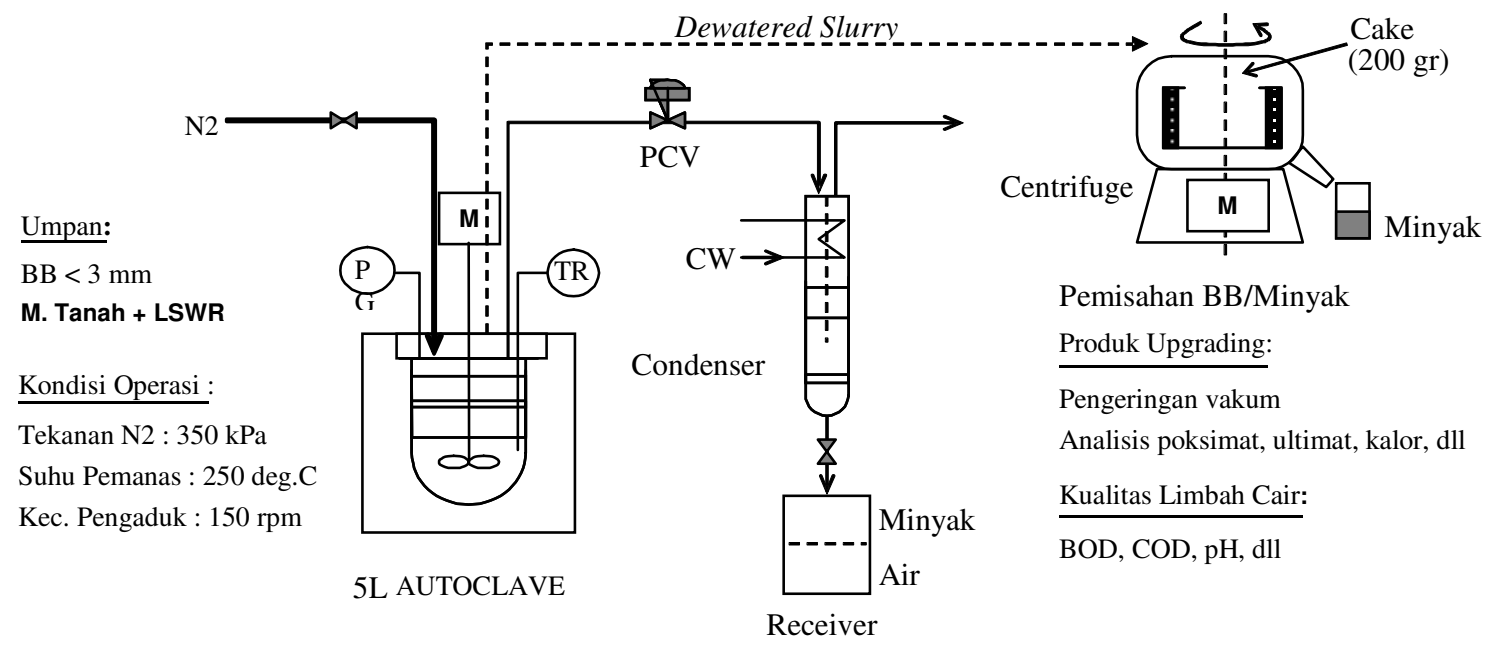

Gambar 1. Skema metode pengujian peningkatan kualitas batubara muda 


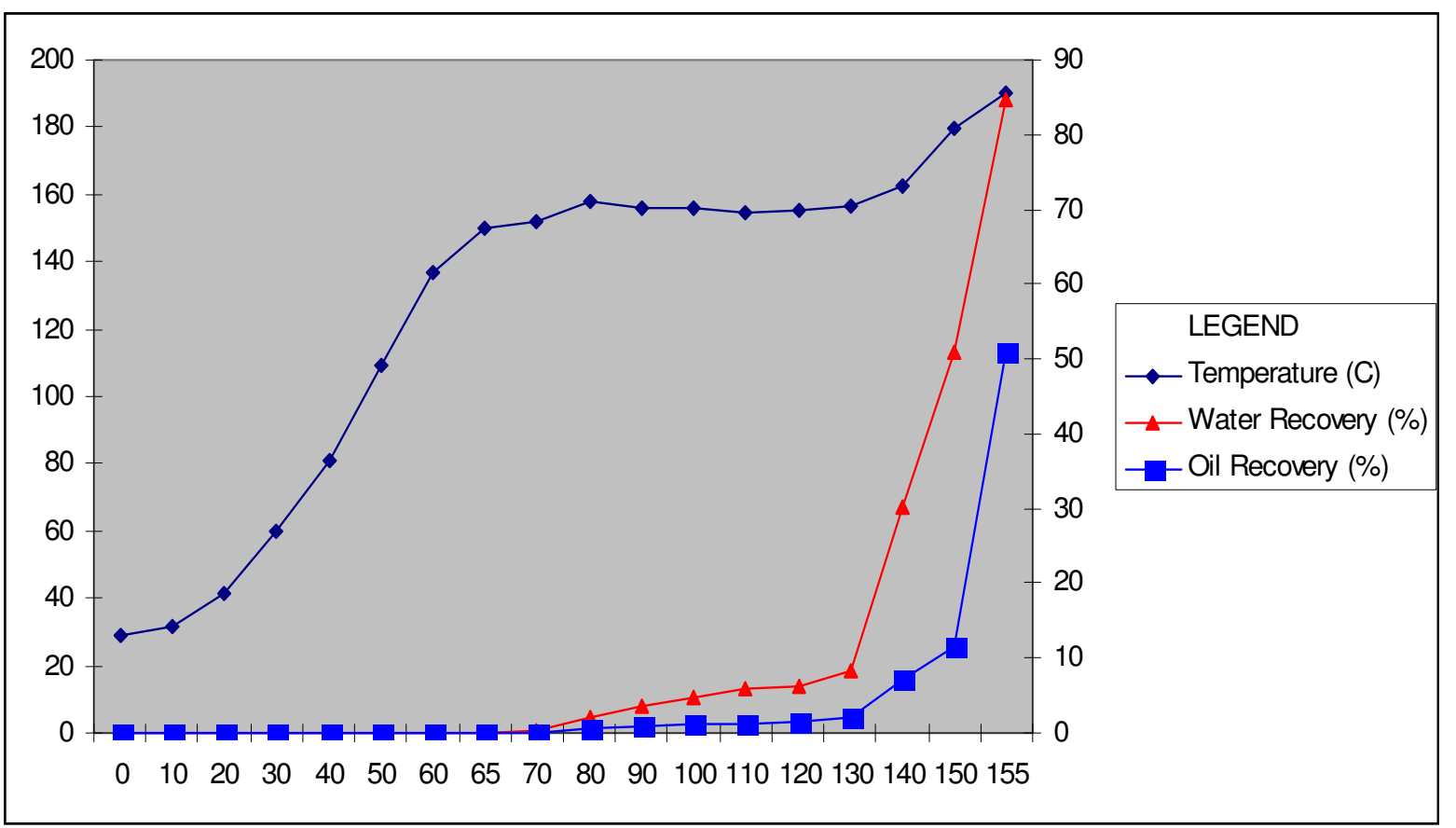

Gambar 2. Rekaman operasi pengujian dengan autoclave 5 liter

\section{Metode Pengujian}

Gambar 1 menunjukkan skema metode pengujian peningkatan kualitas batubara muda. Batubara $1000 \mathrm{gr}$ dengan ukuran partikel $(-4.75 \mathrm{~mm}+2,36 \mathrm{~mm})$ digunakan sebagai sampel. Minyak tanah $(1302,5 \mathrm{gr})$ dan LSWR $(6,5 \mathrm{gr})$ digunakan sebagai pelarut coating. Proses slurry dewatering dilakukan pada kondisi tekanan $3,5 \mathrm{~kg} / \mathrm{cm}^{2} \mathrm{G}$ dengan variasi rasio $\mathrm{O} / \mathrm{C}(1,5 ; 1,75 ; 1,9 ; 2$ berat/berat $)$ dan konsentrasi minyak berat (LSWR) $(0,5 ; 1 ; 1,5 ; 2 \%$ berat dalam minyak). Sebelum operasi, autoclave dibilas dengan nitrogen (3X). Pemanasan elektrik pada $250^{\circ} \mathrm{C}$ dengan kecepatan pengadukan $150 \mathrm{rpm}$, katup pengatur tekanan (pressure control valve) dioperasikan dengan hati-hati untuk mempertahankan tekanan operasi 3,5 $\mathrm{kg} / \mathrm{cm}^{2} \mathrm{G}$.

Operasi dihentikan jika produk air yang keluar dari kondensor lebih dari $90 \%$ dan atau temperatur dalam autoclave mencapai $190^{\circ} \mathrm{C}$. Selanjutnya autoclave di dinginkan sampai temperatur ruang dan produk slurry diambil dari autoclave. Produk air dari kondensor dianalisis untuk mengetahui kadar COD (chemical oxygen demand), BOD (biochemical oxygen demand), TDS (total dissolved solid), TSS (total suspended solid) dan $\mathrm{pH}$ (derajat keasaman).

Separator centrifuge digunakan untuk memisahkan minyak dari slurry batubara (cake). Peralatan ini dioperasikan pada kecepatan 1500 rpm dengan kapasitas 200 gr cake. Produk batubara up-graded dikumpulkan untuk selanjutnya dikeringkan dan dianalisis untuk mengetahui karakteristiknya seperti proksimat, ultimat dan nilai kalor.

\section{HASIL DAN PEMBAHASAN}

\section{A. Profil Kondisi Proses Slurry Dewatering}

Gambar 2 menunjukkan rekaman operasi pengujian dengan autoclave 5 liter. pemanasan awal selama satu jam dilakukan untuk mencapai kondisi saturated pada tekanan konstan $3,5 \mathrm{~kg} / \mathrm{cm}^{2} \mathrm{G}$ sampai temperatur $150^{\circ} \mathrm{C}$ (sesuai data dari steam table). Pada kondisi evaporasi diperoleh total pengambilan air (dewatering) sekitar 10 persen selama 1 jam, sehingga proses dewatering harus dilanjutkan hingga temperatur maksimum $190^{\circ} \mathrm{C}$ pada kondisi superheating. Temperatur maksimum $190^{\circ} \mathrm{C}$ ditetapkan untuk menghindari batubara mengalami proses dekomposisi secara termal. Pada akhir kondisi superheating, diperoleh total pengambilan air (dewatering) sekitar $83 \%$. Keseluruhan waktu operasi dicapai selama 160 menit.

Hasil dari profil kondisi operasi ini juga merupakan bagian dari uji performansi fasilitas peralatan up-grading batubara di Laboratorium Pencairan Batubara, P3TKKEBPPT, Kawasan PUSPIPTEK, Serpong, Tangerang. Hasil ini menunjukkan bahwa proses slurry dewatering dapat diaplikasikan secara efektif untuk batubara muda Indonesia. Dalam pengujian ini unit katup pengatur tekanan menjadi suatu hal yang sangat penting untuk mempertahankan kestabilan proses (tekanan). Dimana dari data dan hasil pengamatan tersebut telah ditetapkan sebuah prosedur khusus untuk pengoperasian katup pengatur tekanan sehingga total dewatering dapat mencapai di atas $90 \%$.

\section{B. Hubungan Rasio O/C Dewatered Slurry terhadap O/C Umpan}

Gambar 3 menunjukkan hubungan O/C (minyak/batubara) hasil upgrading (dewatered slurry) terhadap $\mathrm{O} / \mathrm{C}$ umpan. Pada konsentrasi LSWR $=0.5 \%$ berat dalam minyak diperoleh $\mathrm{O} / \mathrm{C}$ dewatered slurry tertinggi sebesar 1,43 dengan $\mathrm{O} / \mathrm{C}$ umpan=2, sedangkan $\mathrm{O} / \mathrm{C}$ dewatered slurry terendah sebesar 0,78 dengan $\mathrm{O} / \mathrm{C}$ umpan=1,5. Pada konsentrasi LSWR $=1 \%$ berat dalam minyak diperoleh $\mathrm{O} / \mathrm{C}$ dewatered slurry tertinggi sebesar 1,27 dengan $\mathrm{O} / \mathrm{C}$ umpan $=2$, sedangkan $\mathrm{O} / \mathrm{C}$ dewatered slurry terendah 0,87 dengan $\mathrm{O} / \mathrm{C}$ umpan $=1,5$. Pada konsentrasi 
$\mathrm{LSWR}=1,5 \%$ berat dalam minyak diperoleh $\mathrm{O} / \mathrm{C} d e$ watered slurry tertinggi sebesar 1,33 dengan $\mathrm{O} / \mathrm{C}$ umpan $=2$, sedangkan $\mathrm{O} / \mathrm{C}$ dewatered slurry terendah sebesar 0,9 dengan $\mathrm{O} / \mathrm{C}$ umpan=1,5. Pada konsentrasi LSWR = $2 \%$ berat dalam minyak diperoleh $\mathrm{O} / \mathrm{C}$ dewatered slurry tertinggi sebesar 1,42, sedangkan $\mathrm{O} / \mathrm{C}$ dewatered slurry terendah sebesar 0,92 dengan $\mathrm{O} / \mathrm{C}$ umpan $=1,5$.

Rasio O/C dewatered slurry yang diperoleh merupakan faktor yang sangat penting untuk merancang proses, dimana hal ini berhubungan dengan kekentalan campuran bubur batubara (slurry viscocity) sehingga memberikan juga pengaruh yang signifikan terhadap keekonomian proses.

Parameter yang mempengaruhi perancangan proses tersebut antara lain pemindahan panas (heat transfer), penurunan tekanan (pressure drop) dan pola aliran (flow pattern), yang menjadi parameter penting dalam kestabilan pencampuran (mixing) dan pemompaan (pumping) pada peralatan.

Hubungan antara viskositas slurry dan O/C umpan ditunjukkan pada Gambar 4, dimana kenaikan rasio O/C umpan atau fluidity umpan dan dewatered slurry seiring dengan penurunan viskositas slurry dan akan mengalami kestabilan pada rasio $\mathrm{O} / \mathrm{C} \geq 1.4$ (550 centiPoise).

Hasil penelitian menunjukkan bahwa rasio $\mathrm{O} / \mathrm{C}$ dewatered slurry yang lebih besar atau sama dengan 1,4 dapat diperoleh pada kondisi O/C umpan=2, konsentrasi $\mathrm{LSWR}=0,5$ dan $2 \%$ berat dalam minyak. Sedangkan pada kondisi $\mathrm{O} / \mathrm{C}$ umpan=1,9 dan konsentrasi LSWR $=2 \%$ berat dalam minyak diperoleh rasio $\mathrm{O} / \mathrm{C}$ dewatered slurry sebesar 1,37 .

Pengaruh O/C umpan pada kondisi operasi sangat penting guna mendapatkan $\mathrm{O} / \mathrm{C}$ dewatered slurry yang memenuhi persyaratan teknis, sedangkan penambahan konsentrasi LSWR tidak terlalu berpengaruh pada kondisi operasi untuk mendapatkan $\mathrm{O} / \mathrm{C}$ dewatered slurry.

Sehingga dapat disimpulkan bahwa pada kondisi operasi $\mathrm{O} / \mathrm{C}$ umpan $=2$ dan konsentrasi $\mathrm{LSWR}=0,5 \%$ berat dalam minyak dapat memenuhi persyaratan teknis $(\mathrm{O} / \mathrm{C}$ slurry dewatered di atas 1,4) dan lebih baik secara ekonomi.

\section{Karakteristik Umpan dan Hasil Up-grading}

Tabel 3 menunjukkan perbandingan karakteristik batubara umpan dan batubara hasil dari proses slurry dewatering. Hasil analisis tersebut menunjukkan bahwa sifat produk batubara yang dihasilkan tidak banyak mengalami perubahan kecuali peningkatan nilai kalor (sampai sekitar $7300 \mathrm{kkal} / \mathrm{kg}$ ) dan penurunan kadar air secara drastis dari 25,2 \%as received menjadi 4,97 \%as received. Hal ini menandakan bahwa proses up-grading de- ngan slurry dewatering dapat memberikan pengaruh yang signifikan bagi peningkatan nilai kalor batubara muda hingga setara dengan batubara bituminus.

Ditunjukkan pula bahwa kandungan abu, zat terbang, kandungan elemental $(\mathrm{C}, \mathrm{H}, \mathrm{N}$ dan $\mathrm{S})$ dari batubara tidak mengalami perubahan yang berarti. Fenomena ini menunjukkan bahwa tidak terjadi reaksi kimia selama proses upgrading dan penyerapan minyak ke dalam struktur poripori batubara berlangsung dengan baik.

Gambar 5 menunjukkan produk hasil upgrading dengan proses slurry dewatering. Cake adalah produk batubara setelah proses penghilangan air. Sedangkan slurry adalah bentuk umpan batubara campuran dengan pelarut. Ditunjukkan pula bahwa pelarut fraksi berat (LSWR) terabsorpsi secara efektif ke dalam pori-pori batubara.

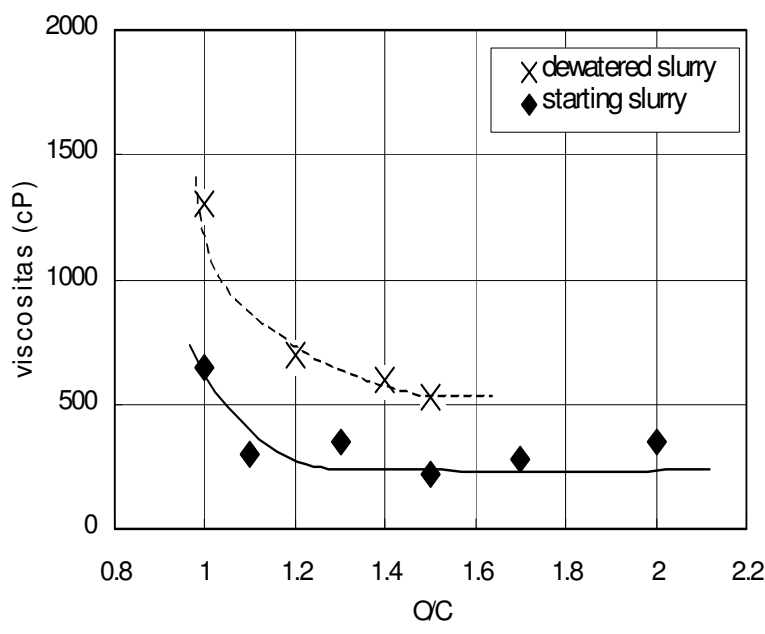

[berat minyak / berat batubara bebas air]

Gambar 3. Hubungan O/C (minyak/batubara) hasil upgrading (dewatered slurry) terhadap O/C umpan

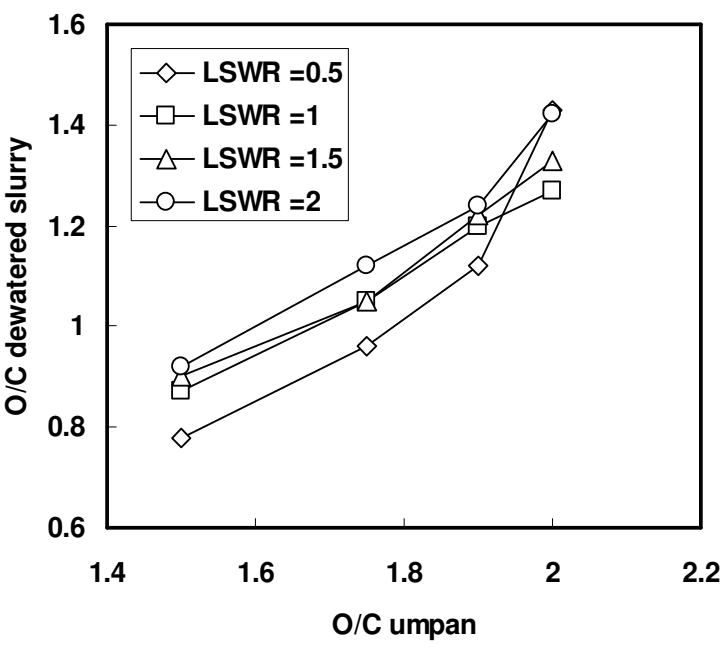

Gambar 4. Hubungan antara viskositas slurry dan O/C umpan 

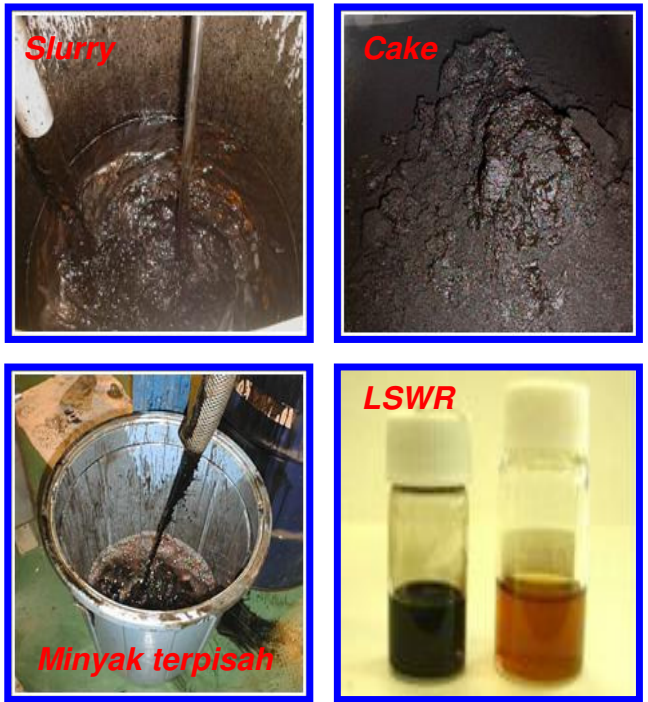

Gambar 5. Produk cake, slurry dan minyak berat

TABEL 3

KARAKTERISTIK BATUBARA UMPAN DAN PRODUK BATUBARA UPGRADED

\begin{tabular}{|l|r|r|}
\hline \multicolumn{1}{|c|}{ Parameter } & \multicolumn{1}{|c|}{$\begin{array}{c}\text { Batubara } \\
\text { Umpan }\end{array}$} & $\begin{array}{c}\text { Batubara } \\
\text { Up-graded }\end{array}$ \\
\hline Total Kand. Air & 25,20 & 4,97 \\
(\% Ar) & & \\
Proksimat (\% db) & 4,66 & 4,81 \\
$\quad$ Abu & 46,14 & 49,61 \\
Zat terbang & 49,20 & 45,57 \\
Karbon tetap & & \\
\hline Ultimat (\% daf) & 73,11 & 78,03 \\
C & 5,17 & 5,75 \\
H & 0,53 & 0,60 \\
N & 2,48 & 2,58 \\
S & 18,71 & 13,04 \\
O (diff.) & 5178 & 7342 \\
\hline Nilai Kalor & & \\
(kcal/kg), Ar & * & \\
Hasil pengujian Lab. KA, B2TE-BPPT, Serpong
\end{tabular}

TABEL 4

Kualitas AIR BuANGAN (LIMBAH CAIR) DARI PROSES SLURRY DEWATERING

\begin{tabular}{|c|c|c|}
\hline Parameter Uji & Nilai & Batas Baku Mutu \\
\hline TDS (mg/L) & 126 & $2000-4000$ \\
TSS (mg/L) & $<0.1$ & $200-400$ \\
pH & 3,43 & $6-9$ \\
\hline
\end{tabular}

\section{Kualitas Air Buangan (wastewater)}

Kualitas air buangan (limbah cair) dari proses slurry dewatering skala laboratorium ditunjukkan pada Tabel 4. Kualitas air buangan ini cukup bersih dengan nilai $\mathrm{pH}$ sebesar 3,4 TDS $126 \mathrm{mg} / \mathrm{L}$ dan TSS < $0.1 \mathrm{mg} / \mathrm{L}$. Nilai ini masih di bawah ambang batas baku mutu limbah cair yang ditetapkan oleh pemerintah (KEPMENLH No. 51/MENLH/10/1995).

Dari data awal ini dapat diketahui bahwa proses slurry dewatering pada skala komersial hanya membutuhkan unit pengolahan air buangan (wastewater treatment unit) yang sederhana dengan beban (load) yang relatif lebih kecil dan relatif aman untuk dibuang ke badan sungai.

\section{E. Re-absorption Produk Batubara Up-graded}

Sifat absorpsi dan sifat menolak air batubara berkait erat dengan kadar oksigen dan sifat kemudahannya untuk dibasahi. Kelemahan sejumlah oksigen berbagai gugus fungsional membedakan batubara peringkat rendah dari batubara peringkat tinggi (misalnya sifat-sifat permukaan, kadar lengas, porositas). Apabila batubara tersebut dipaparkan, kelembaban atau air akan dengan cepat menyerap kembali lengas yang hilang.

Gambar 6 menunjukkan hubungan antara kandungan air dengan lamanya waktu pemaparan dari produk upgraded batubara Berau. Kandungan air produk up-graded batubara Berau pada kondisi awal setelah pengujian sebesar 4,97\%, kemudian dipaparkan pada udara terbuka selama satu hari, terjadi kenaikan kandungan air sebesar $6,72 \%$. Kandungan air up-graded batubara Berau mulai mengalami kestabilan, yaitu tidak menyerap air kembali (re-absorpsi free) pada hari kedua yaitu stabil sekitar $7,5 \%$ selama 13 hari pengujian.

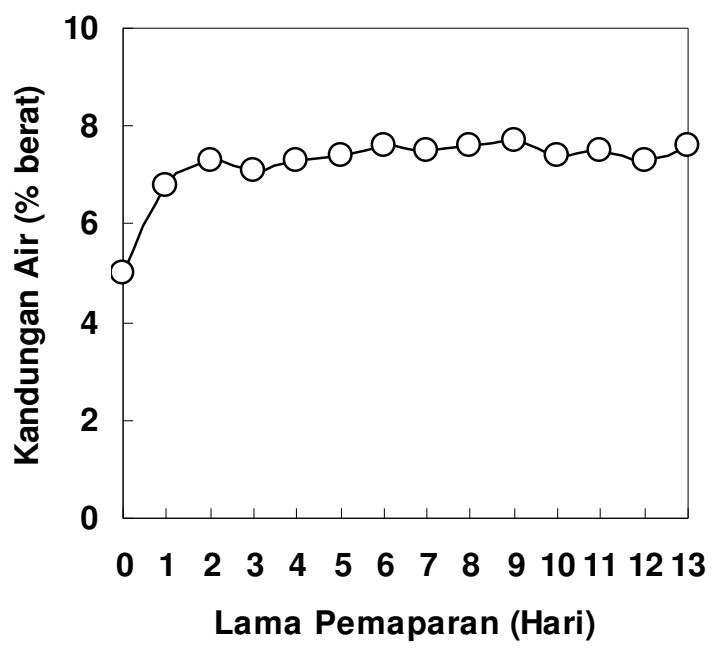

Gambar 6. Pengujian Re-absorpsi kandungan air pada produk upgraded batubara Bera

Sehingga dapat disimpulkan bahwa proses dewatering dan stabilisasi (coating) berlangsung dengan baik, dimana fraksi minyak berat terabsorbsi ke dalam permukaan internal dari pori-pori batubara menyebabkan produk batubara yang dihasilkan tidak mudah menyerap air.

\section{KESIMPULAN}

1. Proses slurry dewatering terbukti menunjukkan performansi yang sangat baik, sehingga dapat di aplikasikan secara efektif untuk batubara muda Indonesia.

2. Total kandungan air (moisture) dari batubara hasil upgrading sebesar $4,97 \%$ as received, dimana terjadi penurunan kadar air yang cukup drastis dari total moisture awal sebesar $25,2 \%$ as received. Terjadi kenaikan yang signifikan untuk nilai kalor pada produk batubara hasil upgrading dari $5178 \mathrm{kcal} / \mathrm{kg}$ menjadi $7342 \mathrm{kcal} / \mathrm{kg}$. Hasil analisa ultimat menunjukkan bahwa pada proses slurry dewatering tidak terjadi perubahan yang berarti antara batubara umpan dan batubara hasil proses tersebut.

3. Air buangan yang dihasilkan dari proses slurry dewatering cukup bersih, sehingga pada tahap komer- 
sial hanya membutuhkan beban unit pengolahan air limbah yang sederhana dan cukup aman untuk dibuang ke badan sungai.

4. Kandungan air batubara hasil upgrading pada pengujian re-absorpsi mulai mengalami kestabilan (tidak mampu menyerap air kembali) pada hari kedua yaitu sebesar $7,5 \%$ berat.

5. Pada kondisi operasi dimana $\mathrm{O} / \mathrm{C}$ umpan $=2$ dan konsentrasi LSWR $=0,5 \%$ berat dalam minyak dapat memenuhi persyaratan teknis $(\mathrm{O} / \mathrm{C}$ dewatered slurry diatas 1,4$)$

\section{DAFTAR PUSTAKA}

[1] Deguchi T, Shigeshisa T., "Development of UBC Process: Upgrading of Low Rank Coal", FTEC International Conference on Fluid and Thermal Energy Conversion, July, 2000.
[2] Deguchi, T, Shigehisa, T., "Demonstration of UBC Process in Indonesia", Coal-Tech Conference Mine Mouth Power Plant, Kobe Steel Ltd., Japan, 2002.

[3] DOE Topical Report, "COMPCOAL - A profitable process for production of a stable high-Btu fuel from Powder River basin coal, DOE/MC/30126-5102", US Department of Energy.

[4] J.A, David., C.Y, Young., Utilization of Low Rank Coals, Envirosafe International Pty Ltd 1a Yarrbat Avenue, Balwyn, Vic 3133, Australia.

[5] Low-Rank Coal Upgrading Technology (UBC Process), Japan Coal Energy Centre; the Institute of Applied Energy; Kobe Steel, Ltd; Nissho Iwai Corp.

[6] UBC Palimanan Project Document, 2003

[7] Van Krevelen, D.W., "Coal: Typology, Physics", Chemistry, Constitution, Elsevier Science Publisher. 1993 